\title{
Determinants of the intention to consume edible insects in Brazil
}

\author{
by Lucchese-Cheung, T., Aguiar, L.K.D., Da Silva, \\ R.F.F. and Pereira, M.W.
}

Copyright, publisher and additional information: This is the authors' accepted manuscript. The published version is available via Taylor \& Francis online.

Please refer to any applicable terms of use of the publisher.

DOI: https://doi.org/10.1080/10454446.2020.1766626

$\mathbf{H}$

Harper Adams University 
WFPM-2020-0005.

\section{Determinants of the Intention to Consume Edible Insects in Brazil}

2

\section{ABSTRACT}

4 Entomophagy has grown in interest as a possible alternative source of protein that could 5 complement future demand for meat products. As a novel food, there are still many 6 barriers to the adoption of entomophagy in western countries. Based on three models, the

7 Theory of Planned Behavior, Expectancy Value and SPARTA a new model is proposed.

8 It takes into account key factors that could most influence consumers about their

9 intentions, rejection and determinant behaviors regarding the extent insects such as

10 crickets and insect cricket protein could replace animal protein in Brazil. Data was

11 collected from a sample of 404 respondents and it was analyzed using Structural Equation

12 Modelling. The results reveal the positive influence of the perceived Behavioral Control

13 and the negative influence of Subjective Norm as the main determinants of the intention

14 to consume insects. The theoretical contribution of the research was the construction of a

15 comprehensive and replicable converged behavioral model for application in the food 16 innovation sector.

18 Key Words: novel foods, entomophagy, theory of planned behavior, crickets. 
WFPM-2020-0005.

\section{Introduction}

2 Feeding an increasing global population will present a great challenge (FAO, 2011) if

3 food systems carry on employing current conventional production methods by 2050 and

4 beyond. Therefore, accessing alternative and more efficient animal protein sources would

5 be of great importance (Gazzoni, 2013). In recent years, the production and consumption

6 of insects as an alternative source of nutrition, particularly protein, has come to light since

7 the publication 'Edible Insects: future prospects' for food and feed security' by the Food

8 and Agriculture Organisation (FAO) (FAO, 2013). It highlighted the potential edible

9 insects had in feeding a growing population and since then, entomophagy has attracted

10 an increased interest in the media, academics and the food industry (FAO, 2013; UN,

11 2018).

12 Tao and $\mathrm{Li}$ (2018) posited that rearing insects for human consumption would be key

13 for food security as it had the potential to supply high-quality animal protein and other

14 valuable nutrients such as fatty acids and minerals (FAO, 2013). Mancini et al. (2019)

15 reviewed several insect sustainability-related claims such as environmental, health and

16 social benefit. In addition, insects reproduce quickly, have a fast growth rate, and are

17 efficient in converting feed into food. Furthermore, insect production techniques require

18 less water; are much less dependent on land and could utilize waste organic material.

19 Insects have been part of the diet of approximately two billion people worldwide

20 (Tao and Li, 2018). In Colombia, Mexico and in the Brazilian hinterland entomophagy is

21 a natural practice amongst some groups (Costa-Neto, 2013). Particularly in Brazil, the

22 consumption of the leaf-cutter queen ant is a key ingredient added to a savory crumble

23 ("farofa") made of manioc flour in northern and north-eastern regions. Despite

24 entomophagy being an established component of food culture among some groups that is

25 not the generalized case for Brazil. In other countries insect eating is an integral part of 
WFPM-2020-0005.

1 the staple diet (FAO, 2013:71), as well as a regional seasonal food habit making it a

2 source of food security (Belluco et al., 2013).

3 Despite existing over 1,900 edible insect species consumed worldwide,

4 predominantly in parts of Asia, Africa and Latin America (FAO, 2013: 9), in many

5 western countries insects as food source have been vilified. In the west, entomophagy is

6 generally regarded as a food taboo. Many perceived it as being a disgusting and primitive

7 act which often destroyed crops (FAO, 2013: 13-35; Costa-Neto, 2013; Cunha et al.,

8 2014). Such a perception in more economically developed western countries has been

9 due to insects being traditionally consumed by populations which lived in tropical and

10 subtropical countries, and that were generally considered less economically developed

11 (Macedo et al., 2017). Corbeau and Poulain (2002) posited that culturally foods are

12 classed as edible and non-edible and such a classification can vary within one country.

13 Hence, the act of considering eating something classed as non-food generates anxiety,

14 fear, aversion and disgust. Fischler (1990) ponders that such a feeling is common among

15 omnivores since to keep alive depended on varied sources of food. Therefore, foodstuff

16 has been classed according to mental categories: edible and non-edible. Such separation

17 helped diminish the anxiety generated when people faced the diverse range of food

18 possibilities particularly regarding the new or unknown. As a result, something which is

19 not usually recognized as familiar or inedible is likely to be rejected for it emulating a

20 primitive, barbaric or repugnant behavior (Fischler, 1990; Mignon, 2002).

21 It is being proposed here that the theoretical basis of this article is the omnivorous'

22 paradox (Fischler, 1990) where the attraction and the distrust of a new food are always

23 actual feelings which naturally provoke anxiety in relation to the new food source. Veeck

24 (2010) explained that due to the advances of modern agriculture and the recent

25 developments in the food manufacturing sector, urban consumers have been exposed to 
WFPM-2020-0005.

1 a wide diversity of foods. For such urban consumers, to deal with the new has become a

2 habit. Nevertheless, the inherent anxiety when facing a novel food is still present since

3 the omnivorous paradox has not disappeared. Moreover, bearing in mind that the act of

4 food consumption is a social one, the contextual effect at consumption when a novel food

5 is introduced cannot be neglected. Therefore, the context around an introduction is

6 influenced by the adoption or rejection as a result of individual and peer's evaluation.

7 In the light of the pressing issues around the increased demand for meat in the future

8 and the extent traditional meat production will impact future food production

9 sustainability, it is important to investigate the degree consumers would be willing to

10 accept alternative protein sources in Brazil. Duo to the considerable meat production

11 capacity in that country, Brazilian consumers are among those with the highest meat

12 consumption trends in the world (USDA, 2020). Therefore, finding alternative sources of

13 protein that would have a lower environmental impact in the future is important. Yet,

14 among the alternative meat proteins available, edible insects are still a novelty in Brazil.

15 The Brazilian population is not used to eating this type of protein despite there being

16 some very localized cases of entomophagy in remote areas of the countryside. The

17 Brazilian population being predominantly urban, the food consumption habits are

18 comparable to many other western countries.

\section{Review of the Literature}

21 In many western cultures, entomophagy typically triggers neophobic reactions of disgust

22 despite edible insects being widely consumed by many cultures (Rozin and Fallon, 1987;

23 La Barbera et al. 2018). Often, consumers can express feelings of fear, disgust and

24 rejection when introduced to a new food product, which is an indicator of the extent

25 consumers, are reluctant to eat unfamiliar foods. Pliner and Hobden (1992) suggested 
WFPM-2020-0005.

1 that fear and rejection were characteristics of a neophobic process where the displayed

2 behavior could be explained through the meaning consumers conveyed based on the

3 Adaptive Value a food might represent to them. That was part of a natural self-

4 preservation behavior developed during the long human evolution history (Alley and

5 Potter, 2011). Furthermore, one's willingness and readiness to try new foods can widely

6 differ between individuals (Balzan et al., 2016). Whilst some may experience high

7 aversion to new foods, others might enjoy experimenting them (Ritchey et al., 2003;

8 Paupério et al., 2014). Yet, in today's society, aversion behavior could also create a

9 potential hostile environment around new product development since food neophobia

10 tend to mostly affect truly innovative new product launches. As a result, introducing new

11 insect-based food products to market could be fraught of barriers as many new product

12 launches fail (Khan et al., 2017). Therefore, consumers' acceptance regarding the

13 consumption of insects as a reliable source of protein (Verbeke, 2015) acted as a main

14 barrier for the diffusion of entomophagy in western countries. Moreover, van Huis et al.

15 (2013) proposed that unfamiliarity and innovation thus limit the intention to consume,

16 hence the lack of familiarity acted as a barrier for consumers adopting insects as food.

17 Rozin and Fallon (1980) proposed there were three main motivations that guided an

18 individual's decision to reject regarding to what they considered as inedible: sensory

19 properties for example bitter taste in foods, green color in meat; the capacity to anticipate

20 negative consequences of ingesting something that might cause discomfort which could

21 cause nausea, allergy and illness; what would be considered an ideal type of food against

22 the general moral norm and beliefs of unsuitability.

23 Gallen et al. (2018) studied the cognitive mechanisms of French consumers regarding the

24 acceptance of a disruptive food innovation such as insects. They considered insects to be

25 a disruptive source of food for them to being new to the French consumers and not being 
WFPM-2020-0005.

1 part of their cultural set of values. They found that the act of thinking about insects

2 provoked a rupture of the mental representations' consumers had when presented to a

3 novel food. To lower down the barrier, it would be required to understand the extent the

4 accepting of an innovation would represent changes in consumption behavior as well as

5 how it would be interpreted as a benefit.

6 Yet, it is of interest to better understand the extent how either product adoption or

7 rejection works for a specific population as it helps to elucidate the motivations behind

8 entomophagy and neophobia. Therefore, three main concepts explaining consumers'

9 behavior will be analyzed. Firstly, the Theory of Planned Behavior (TPB) proposed Ajzen

10 and Fishbein (2000) has been widely used to analyze consumer behavior, especially

11 associated to food choices (Lobb et al., 2007). According to Ajzen and Manstead (2007),

12 the contribution made by the TPB was that it helped predict intentions, resolves, and

13 measured the degree of the intention-behavior relationship (Ajzen, 2011). TPB also

14 allowed for the measuring of the Willingness to Consume a product, the readiness, of

15 something that had still to be introduced to the market. Provided a new food was within

16 the reach of its consumers, the TPB helped explain the extent Social Factors such as

17 beliefs, traditions, culture and family (Cooke and French, 2011) had in influencing

18 consumption intention. Furthermore, Ajzen and Manstead (2007) proposed human

19 actions were driven by Intention and that intention acted as an immediate precursor of

20 behavior. That, in turn, was influenced by Personal Attitude, Subjective Norm and

21 perceived Behavioral Control. That meant individuals constantly assessed favorable and

22 or unfavorable behaviors (Menozzi et al., 2017). The more favorable the subjective

23 attitude and norm was, the greater the perceived behavioral control, and the stronger

24 would be the intention to express such behavior (Ajzen and Manstead, 2007). The TPB

25 also acknowledges that subjective psycho-social determinants act as Predictors. These 
WFPM-2020-0005.

1 determinants are Individual, Social, and Information predictors of behaviors (Ajzen,

2 2017) which support the Behavioral, Normative and Control beliefs. The final expression

3 of behavior resulted from the sum of values expected from the anticipated consequences

4 of the behavioral performance (Cook et al., 2002). Hence, constructs such as personality,

5 experience, culture, ethnicity, and media could directly influence an intended behavior.

$6 \quad$ Yet, that was not enough fully explain a predictive behavior since to better explain

7 an attitude, the Expectancy-Value theory (EV) served to elucidate human expectations

8 and beliefs in relation to a specific object under scrutiny, an attribute, which might attract

9 either favorable or unfavorable ratings. According to the EV theory, attitudes could be

10 explained as an individual's tendency to respond to the rating of an object either favorably

11 or not (Ajzen, 2008). Therefore, the evaluative reaction to an object represented the core

12 of an attitude. Such a reaction, in turn, was based on an individual's expectations or

13 beliefs about that object. The relationship between beliefs and attitude is integral part of

14 the EV model. In it, human attitudes were spontaneously driven by beliefs located in

15 accessible memories, according to the motivation and context in which they were stored.

16 Beliefs were explained as subjective probabilities of an attitude and that the resulting

17 action (object) had a positive or negative rating regarding its intention which was later

18 expressed in the behavior (attribute) (Ajzen, 2008; apud, Fishbein and Ajzen, 1975).

19 Moreover, individuals might build many beliefs about a given object, but only part of

20 those influenced attitudes, which Ajzen (2008) called 'accessible beliefs'. In the EV

21 Model, the individual assessment (attitude) was determined by accessible beliefs about

22 an object, however, Ajzen and Fishbein (2000) proposed them as 'subjective

23 phenomena'. For example, someone may believe that eating insects (object) was unsafe

24 (attribute), given the information (belief) that has been passed down over the years. Thus,

25 the EV model could be a good tool to test predictions about a new food, since providing 
WFPM-2020-0005.

1 new information affected consumers' accessible beliefs. Therefore, a preventive action

2 could be taken regarding the issues concerning the object. This is of relevance because

3 Lensvelt and Steenbekkers (2014) concluded that providing consumers with information

4 and education (Schardong et al., 2019) about insects as well as with exposure to taste it

5 (Woolf, 2019) helped to influence their attitude toward it.

6 The EV model would also allow for the measurement of the variables that were

7 likely to most determine an attribute and that were directly related to an attitude.

8 Therefore, the EV model supported the inclusion of external variables (risk, confidence,

9 culture, ethnicity, religion, family, etc.) in accessible beliefs, thus varying the behavior,

10 whether positively or negatively (Ajzen and Fishbein, 2000). Yet, since attitude in the EV

11 model was influenced by external variables such as subjective norms, risk, and trust,

12 which would determine consumers' intention to buy and consume something, it would be

13 still the case to be built for considering the SPARTA model (Mazzocchi et al., 2006).

14 This is because the SPARTA model (Lobb et al., 2007; Mazzocchi et al., 2006)) could

15 further complement what would be expected from a behavior as it predominantly focused

16 on risk perception and confidence within the TPB. The SPARTA Model emerged from

17 the context integration of risk and trust perception in the TPB and the influence of

18 individual and social determinants. Factors such as risk and trust are especially necessary

19 whilst assessing food as they have a high weight in studying consumers' behavior,

20 particularly the extent it might affect consumers' health.

21 As described in the SPARTA model, trust could be explained as it being a construct

22 that influenced the purchase intent and of paramount importance for the development of

23 innovative food products containing, for example, edible insects. Fishbein and Ajzen's

24 (2010) SPARTA model also used risk as a variable, which could be determined by the

25 Real Behavioral Control (RBC). For example, a consumer might feel confident about 
WFPM-2020-0005.

1 consuming edible insects when they have been informed about the likely health benefits

2 insects might have and, therefore, believed that they had control over such behavior.

3 However, it is possible that when consumers came across insects as food, they perceived

4 the situation as uncomfortable, thus refraining from the action of consumption, which

5 would ultimately make them repress such behavior. Thus, although the perceived

6 behavioral control contributed to consumers having the behavioral intention to consume

7 edible insects, the real behavioral control prevented them from carrying out such action.

\section{Converged Model}

9 Based on Ajzen (2017) TPB model is helpful to analyze the extent a novel food product

10 such as insects would be consumed. It could explain the predictors connected to

11 behavioral beliefs, Subjective Norm and behavioral control (dotted lines) because these

12 are external to the model. Moreover, the beliefs from TPB and SPARTA (perceived

13 behavioral control; attitude, subjective norms, perceived risk, trust and socio-economic

14 demographics) are also part of the internal variables as set out in the EV model. As a

15 result, it would be expected that converging the TPB, EV and SPARTA models into one

16 (Figure 1) would serve to ascertain predictors to consumption intention on how insects

17 could replace traditional animal proteins.

[FIGURE 1 near here]

Little has been investigated about the topic in developing countries (Graça et al.,

22 2015; Sabaté and Soret, 2014; de Boer et al., 2014; Schosler et al. 2012). The most recent

23 publication by (Schardong et al., 2019) brings to light some aspects of entomophagy in

24 Brazil. According to Tilman and Clark (2014) in emerging economies where incomes 
WFPM-2020-0005.

1 have been rising and nutrition transition is happening at a fast pace, it was important to

2 gather more empirical data about entomophagy.

As aforementioned, a converged behavioral model can be used to ascertain the

4 intention and the determinant behaviors driving the consumption or rejection of a novel

5 product such as insects and insect protein (Lobb et al., 2007). Schardong et al. (2019)

6 found in a Brazil country wide study that the respondents lacked familiarity with insects

7 and tended to be neophobic regarding including edible insects in their diet. Despite this,

8 a few respondents mentioned to have already consumed insects at some point in the past.

9 Those were mostly men, with women showing a greater aversion to consuming it.

10 Nonetheless, considering the production and consumption of insect protein is still a

11 novelty, particularly for most of the Brazilian population, this study aimed to bring to

12 light the likely intentions and motivations behind entomophagy. Thus, the overarching

13 aim of this study is to ascertain the key factors determining the intention to eat crickets in

14 Brazil. To do this, a converged model of consumers' intention to consume a novel food

15 such as insects was conceived. It tested the extent an alternative source of animal protein

16 could replace red meat protein in the future using an important emerging economy such

17 as Brazil.

18 Method

19 Despite the range of edible insects mentioned in the literature, for the purpose of this

20 study, the notion of dried industrially processed crickets was used as refence for them

21 being the most studied regarding entomophagy. The study was carried out in the center-

22 west region in Brazil, in the capital city Campo Grande, in the state of Mato Grosso do

23 Sul. The region is characterized by intensive crop and livestock production which

24 during the 1970s and 1980s was an area of agricultural expansion frontier where people

25 from many Brazilian states converged into. A cross-sectional survey questionnaire was 
WFPM-2020-0005.

1 used to collect primary data, which according to Malhotra (2011) was the most suitable

2 formal and structured method for obtaining information applied to respondents. The

3 questionnaire was prepared based on the review of the literature and used measuring

4 scales that have been already tested and validated. This research was funded by the

$5 \quad$ National Service for Industry (SENAI) and the Foundation for Technological

6 Development of Mato Grosso do Sul (FUNDETEC) whose Ethics Committee also

7 approved it under FUNDETEC Project 2.437.712/17.

\section{Data Collection}

9 Data was collected between October to December 2017. An established commercial

10 marketing polling company was used to collect information. The sample was subjected

11 to socio-economic stratification following the Brazilian Institute of Geography and

12 Statistics (IBGE) demographics dataset (IBGE, 2018). Thus, the respondents were

13 representative of a range of demographic background (income, education, age). In order

14 to participate in the survey, the respondents needed to be at least twenty years old as

15 proposed by Tuorila et al., (2001) and Verbeke (2015). The sample size was defined as

16 suggested by Hair et al. (2009), who stated that a solid analysis required 5 to 10

17 respondents for each parameter estimated in the model; as there were 67 scale items, the

18 minimum sample size needed should be 335 respondents. The questionnaires were

19 collected from main urban public areas such as shopping malls, supermarkets and

20 neighborhoods. Trained interviewers contracted by a polling company and following their

21 data quality protocol annotated all the answers hence guaranteeing accuracy and

22 reliability of the answers. In total, data was collected from 404 individuals which more

23 than satisfied the minimum sample size requirement.

24 The dependent variable used was the Intention to Consume edible insects, crickets,

25 which would be explained by independent variables such as: Perceived Behavioral 
WFPM-2020-0005.

1 Control, Subjective Standard Attitudes, Trust, Perceived Risk, Neophobia andSocial-

2 Demographic- Economic factors. In order to quantify the variables, a Likert type scale

3 (1-7) was used, as the wider range of answers encouraged heuristic decisions (Dalmoro

4 and Vieira, 2013; Silva and Costa, 2014). That meant the respondents upon choosing an

5 answer had to access their beliefs in relation to what was requested from them by the

6 questions asked. The respondents would seek to respond more positively or negatively to

7 a statement instead of opting for the neutral response (such as "I do not know how to

8 respond"), thus increasing the reliability of results.

9 The questionnaire design used attributes such as those proposed by Steptoe et al.

10 (1995), Pliner e Hobden (1992), Bearth et al. (2014), Rozin (2014) and Sogari et al.

11 (2018) tested in studies during which the scales had been validated and widely accepted

12 by the literature. Other attributes were included such as 'willingness to try' or 'willingness

13 to consume' in an attempt to capture a new behavior such as entomophagy. The constructs

14 were validated through the convergent and discriminant validity test, which was

15 measured by the mean variance extracted from each construct and whose value should be

16 above 0.5 (Hair et al., 2009). The reliability of the constructs was verified by the

17 Cronbach alpha and composite reliability, with recommended values above 0.7 (Fornell

18 and Larcker, 1981).

19 Data Analysis

20 The analysis was carried out using the confirmatory factor analysis and the Structural

21 Equation Modelling (SEM), through the Stata software, version 14. The database

22 included latent variables (constructs), measurable variables and their respective factor

23 loading. Thirty-six observable variables were used to determine the six latent constructs,

24 which were estimated as determinants of the intention to consume edible insect (cricket),

25 represented by squares (observed variables) and circles (constructs), respectively. In a 
WFPM-2020-0005.

1 population sample whose respondents are not very acquainted with the idea of

2 entomophagy, measuring consumers' intention is important as it is also a latent construct

3 and was measured by ten observable variables.

The application of the structural equation modeling methodology was based on the

5 literature to explain the interrelationship between a set of variables, which can be

6 dependent (endogenous) or independent (exogenous). Thus, theoretical models could be

7 tested using such a modelling, since it was possible to evaluate how the set of observed

8 variables defined unobservable ones (constructs), and how these constructs related to each

9 other (Amorim et al., 2012; Schumacker and Lomax, 2010). The SEM also allowed an

10 analysis of the adjustment indices of the model, to check data consistency in relation to

11 the theory. The indices were: RMSR, RMSEA, TLI and CFI; Amorim et al., 2012).

12 The model proposed herein sought to identify the relationship between the 13 determinants perceived behavior control (F1), attitude (F2), subjective standard (F3), trust 14 (F4), perceived risk (F5), social, demographic and economic aspects (F6)), as well as 15 intention. .

Reliability and Validity of Constructs

To check the convergent validity of the constructs, the standardized factor

20 loadings for each observed variable were analyzed, as shown in Table 3 . The higher the

21 factor loading, the stronger is the evidence that the measured indicators represent the

22 constructs to which they are associated, hence showing consistency and indicating a

23 convergent validity. Furthermore, the reliability of the constructs (Cronbach alpha) and

24 the internal consistency (Composite Reliability) were calculated and the values show that

25 most of the constructs used in the Ultimate Model met the minimum reliability levels 
WFPM-2020-0005.

1 deemed appropriate by literature with values above 0.7 , for both the Cronbach alpha and

2 the Composite Reliability. While the Perceived Behavioral Control (F1) (0.9381),

3 Subjective Norm (F3) (0.7792), Perceived Risk (F5) (0.7475) and Intention (INT) (0.977)

4 were significant, the exception was the Social-Demographic-Economic construct (F6),

5 which presented an approximate value in the composite reliability of 0.6504

6

7

8 As for the constructs Perceived Behavioral Control (F1) and Intention (INT) the alpha

9 Cronbach value was 0.8802 and 0.9559 respectively thus showing a relative high internal

10 consistency. The convergent validity was also analyzed through the Average Variance

11 Extracted (AVE) which shows the portion of the data of the variables that is explained by

12 each of the corresponding latent construct. The recommended value for AVE should be

13 greater than or equal to 0.5 (Nascimento and Macedo, 2016; Ringle et al., 2014) which

14 in this case of this study the value obtained was 1.

15 The divergent validity was also calculated and and it shows the main diagonal as

16 the AVE for each construct, and the other are cells with the square of the correlation

17 coefficients between each pair of constructs (shared variances). The divergent validity

18 will be present if the correlations between the latent variables are lower than the square

19 root of the AVE (Nascimento and Macedo, 2016; Ringle et al., 2014). It is observed that

20 all the shared variances were lower than the variance extracted by the items that measure

21 the constructs, indicating a proper divergent validity.

\section{Results}

23 In Model 1, six latent constructs which may determine an intention were analyzed. After

24 estimation and the analysis of fit indices were carried out to verify which ones would be

25 best suited for the proposed model, a second model, Model 2, was analyzed aimed at 
WFPM-2020-0005.

1 finding a better balance between the latent variables. Model 1 comprised of all the

2 proposed constructs. Since the adjustment indices of the Structural Equation Modelling

3 did not show to have a direct statistical significance to support that model, Chi-squared

4 statistic was used to evaluate the theoretical model. In Table 2, other composed measures

5 such as: RMSR, RMSEA, TLI and CFI (Léon, 2011; Amorim et al., 2012) were also

6 carried out.

7

8

9

10

11

12

13

14

15

16

17

18

19

Perceived Behavioral Vontrol (F1), Subjective Standards (F3), Perceived Risk (F5) and

24 Social, Demographic and Economic factors (F6). To ascertain the validity of the

[TABLE 2 near here] 
WFPM-2020-0005.

1 estimated Models 1 and 2 analyzes of the RMSEA, RMSR, TLI, CFI and $\chi^{2}$ indices of

2 the models as a whole were carried.

3

[Table 1 near here]

From Figure 2, it can be seen that six hypotheses were rested and only $\mathrm{H} 1$ 'The more positive is the perceived Behavioral Control in relation to the product, the higher would the intension to consume be', and H3 'The more the individuals are influenced by Positive Subjective Norms in relation to the product, the higher would the intention to consume be' were not rejected. The $\chi^{2}$ index determines whether the predicted covariance matrix fits the sample covariance matrix, and whether a low value leads to a non-rejection of the hypothesis zero (H0) thus meaning a good fit of the model. The $\chi^{2}$ index obtained was significant for both models, indicating that they were designed correctly, since their value was 0.0000 , showing a good fit and non-rejection of $\mathrm{H} 0$. The RMSEA (Root Mean Square Error of Approximation) index serves to estimate how the parameters of the model reflect the population's covariance. The closer the index value to 0.05 or below it means that the model accurately reflects the population's covariance therefore a good fit. The RMSEA values for both Model 1 and Model 2 were 0.1014 and 0.1146 respectively which means a poor fit. Therefore, it can be concluded that the models did not show a good performance. Nonetheless, the Root Mean Residual Square index (RMSR) calculated generated a value of 0.067 for Model 1 and 0.0146 for Model 2. Since both RMRS values are close to zero they are thus is considered to be a perfect fit.

When the TLI (Tucker-Lewis Index) was calculated to test the extent the addition of more estimated parameters that might worsen the fit of the models. In this case, the indexes represented a good and discrete fit for Model 1 (0.8353), and a very good fit for Model 2 (0.8990). 
WFPM-2020-0005.

1

2

3

The CFI (Comparative Fix Index) was also calculated to guess the relative improvement in the fit of the estimated model against a standard one. In this CFI index case a value closer to 1 indicates a better fit of the model. As a result, Model 1 resulted in a CFI of 0.8902, thus representing a good fit, and Model2 an index of 0.9495 which is also a very good fit. Considering the analysis of the fit indices, we can conclude that Model 2 has a much better fit to the constructs rather than Model 1 for RMSR, TLI and CFI thus supporting the notion it is a valid model to be used.

Model 2, or the ultimate best fit model. was validated by the probability of the Chisquared (Prob> $\chi^{2}$ ) being 0.000 and the $\chi^{2}$ value of 350.84 which was significant at $1 \%$. Therefore, it can be concluded that Model 2) was well fit.

\section{Discussion}

When investigating the consumers' intention to eat insects as an alternative food source, namely, the causal relationship between the factors (perceived behavioral control, Subjective Norm, perceived risk, neophobia and socialdemographic-economic factors) and the consumption intention, the Perceived Behavior Control found (F1) [0.36] was the only variable to positively influence the assessment of that intention. Whilst in the same sample the Subjective Standard aspect (F3) [-1.03] negatively influenced the assessment of the consumption intentions. These two aspects were only significant regarding the causal relationship with the intention, which meant that the other aspects were not significant at $1 \%, 5 \%$ and $10 \%$.

It was possible to observe that a positive influence of Perceived Behavioral Control on Intention in the case when the higher the recommendation (F1.1) [1.00], the more 
WFPM-2020-0005.

1 information was disseminated by the media (F1.2) [0.45], the greater the need/concern

2 with the future (F1.3) [0.81], resulting in a greater Intention present in the sample studied.

3 This is in line with the concept developed by Menozzi et al. (2017), in which the intention

4 was driven by the perceived behavioral control.

It was found that the influence of Perceived Behavioral Control acted on the

6 Intention to consume edible insects [0.8802]. This agrees with what Alemu et al. (2017)

7 proposed in their study on the preference of Kenyan consumers for insect foods such as

8 termites. That study also showed that the Recommendation variable was of great

9 importance, and positive recommendations were important in determining the preference

10 for termite food products in Kenya. It also showed that consumers needed more

11 information on the subject to raise their likelihood to consume it. In that case the media

12 influenced the perceived control over food, something also identified in this study.

13 The negative influence of Subjective Norm (F3) in the consumption intention, i.e.

14 the more individuals were influenced by negative Subjective Norm concerning the

15 product, the more negatively would the influence on the consumption intention be. The

16 Subjective Standard construct comprised the variables culture/tradition (F3.1) [1.00],

17 familiarity (F3.3) [0.69] and social acceptance (F3.5) [0.60] as being the most significant

18 due to factor loading. It could then be concluded that such a negative relationship

19 occurred because the consumption of insects was not yet a reality in the geographical area

20 covered by the sample. Data was collected from a province in Brazil where beef cattle

21 production is an important economic activity and the consumption of meat is very high

22 (Vigitel, 2015). Furthermore, due to the respondents sampled lacked prior knowledge

23 (accessible beliefs) on consuming insects as an alternative source of food, it could be

24 inferred that alternative sources of protein did not constitute an eminent necessity. 
WFPM-2020-0005.

1

Verneau et al. (2016) in a two-country study found communication of the subject, particularly regarding social and individual benefits that encouraged consumers to eat insect-based foods, to be affected by food culture. In two different countries such as Denmark and Italy, the respondents were also influenced by Subjective Norm in the consumption intention, and familiarity (previous knowledge) which was highly and positively correlated with the intention to consume insects. Similarly, Cicatiello et al. (2016) found that in Italy familiarity (past experience) acted as a positive factor influencing the intention to consume insects which was also supported by Lensvelt and Steenbekkers (2014), Schardong et al. (2019) and Woolf (2019).

Nevertheless, Pas (2017) in the Netherlands, analyzed familiarity from a different angle. Familiarity was understood as familiar foods containing insects, rather consumers having prior knowledge on the subject that negatively affected their intention to consume. Therefore, the Dutch preferred unknown products with invisible insects rather than familiar products containing them. The negative association of food familiarity with the presence of insects was also observed by Tan et al. (2015) in a study carried out both in Thailand and the Netherlands. Insects present in familiar foods raised negative associations, as the insects were seen as pests and disease carriers. As for the relationship of familiarity to a food and the presence of insects, Tan et al. (2015), when comparing attitudes between Thailand and the Netherlands, found that familiarity had a negative value in the latter whilst in Thailand it was positive. A plausible explanation for this being the higher frequency the Thai population consuming insects.

Castro and Chambers (2019) conducted an international study analyzing 7,800 consumers from thirteen countries including Brazil. They found the greatest barrier tended to be due to anxiety related to eating insects thus caused, firstly, by neophobia and secondly by the lack of information about product safety. When questioned about their 
WFPM-2020-0005.

1 disposition to experiment familiar foods with added insect flour, 50\% of the Brazilian

2 sample were classed as 'accepting'. Yet, no further analysis was carried out on the

3 Brazilian sample on the 'acceptors' since the other $50 \%$ of the respondents rejected such

4 an idea (Castro and Chambers, 2019).

Culture/tradition and social acceptance were also studied by Hartmann et al. (2015).

6 They observed the variables were significant and negative respectively. They concluded

7 that Subjective Norm negatively influenced the consumption intention which was also

8 observed in this study [-1.03]. This was also supported by Schardong et al. (2019) in their

9 nationwide survey in Brazil. Furthermore, Hartmann et al. (2015) who compared

10 consumers' intention to eat edible insects based on factors such as cultural and social

11 acceptance as part of a subjective construct in Germany and in China found a similar

12 result. The Chinese tended to have a positive intention towards the consumption of

13 insects, because insects as food were recurrent in China while in Germany the intention

14 was negative, thus agreeing with Tan et al. (2015).

16 Conclusions

17 The study adds to the literature on entomophagy for its novelty in the location of the research and for its originality. As for the contribution of this paper is twofold: firstly, in

19 the construction of a more comprehensive and replicable Converged Model to measure

20 intention in the food innovation sector; secondly, bringing to light the likely intention to

21 consume edible insects based on a population which is not yet exposed to

22 entomophagy.

23 The perceived Behavioral Control and Subjective Norm were the most influential

24 constructs in the intention to consume insects. Whiles the former influenced positively,

25 the latter negatively. The most significant variables observed for each construct were: 
WFPM-2020-0005.

1 Recommendation, Need/Concern about the future, As for the Subjective Norm, the

2 barriers to consumption could at the same time positively as well as negatively

3 affecting the Perceived Behavioral Control.

It is worth highlighting that, following the answers to Question 7 and Question 8

5 which measures intention to insect insects disguised or whole, it could be inferred that

6 the respondents would rather accept food products with insects disguised as an ingredient

7 [factor load 0.49] such as insect flour rather than whole [factor load 1.02] as there were

8 no visual cues for the presence of insects.

9 It is worth also highlighting at that many of the respondents in this study had not

10 yet been exposed to consuming insect-enriched products, thus it is acknowledged as a

11 limitation. Moreover, data collected in the capital city of a prominent center-west state

12 such as Mato Grosso, Campo Grande, could be a good representation of the Brazilian

13 population for the demographic diversity resulting from internal migratory movements in

14 Brazil in the 1980s.

15 The creation of a model based on key consumer behavior theories is of value

16 particularly for those in the food sector due to re-emerging of entomophagy in recent

17 years. The findings from the application of the model have a direct application for food

18 manufacturers aiming at developing innovative products using insect protein in Brazil.

19 The widespread consumption of insect products in Brazil could also bring immense

20 potential benefits to the health of the population and the environment, not to mention for

21 generating income and creating jobs.

23 References

24 ALLEY, T.R. \& POTTER, K.R. 2011. In Preedy, V.R., Watson. R.S. and Martin, C.R.

25 (eds) Chapter 47, Food neophobia and sensation seeking. The handbook of behavior, 
WFPM-2020-0005.

1 food and nutrition. Springer, 707-724.

AJZEN, I. 1991. The theory of planned behavior. Organisational. Behavior. Human. Decis. Process. 50, 179-211.

AJZEN, I. 2008. Consumer attitudes and behavior. In Handbook of consumer psychology, $525-548$.

AJZEN, I. 2011. The theory of planned behaviour: reactions and reflections. Psychology and Health, 26(9), 1113 - 1127.

AJZEN, I. 2017. Figura Teoria do comportamento planejado (TPB). Retrieved from http://people.umass.edu/aizen/tpb.diag.html

AJZEN, I., and FISHBEIN, M. 2000. Attitudes and the attitude-behavior relation: reasoned and automatic processes. European Review of Social Psychology, 11(1), $1-33$.

AJZEN, I. \& MANSTEAD, A. S. R. 2007. Changing health-related behaviours: an approach based on the theory of planned behaviour. In The scope of social psychology: Theory and applications. (pp. $43-63$ ).

ALEMU, M. H., OLSEN, S. B., VEDEL, S. E., PAMBO, K. O. \& OWINO, V. O. 2017. Combining product attributes with recommendation and shopping location attributes to assess consumer preferences for insect-based food products. Food Quality and Preference, 55, 45 - 57.

AMORIM, L. D. A. F., FIACCONEe, R. L., SANTOS, C. A. S., MORAES, L. T. L. P., OLIVEIRA, N. F., OLIVEIRA, S. B. \& SANTOS, T. N. L. 2012. Modelagem com equações estruturais: princípios básicos e aplicações (Estatística). Universidade Federal da Bahia.

BALZAN, S., FASOLATO, L., MANIERO, S. \& NOVELLI, E. 2016. Edible insects and young adults in a north-east Italian city an exploratory study. British Food 
WFPM-2020-0005.

Journal, 118, 318 - 326.

BEARTH, A., COUSIN, M. \& SIEGRIST, M. 2016. The dose makes the poison": informing consumers about the scientific risk assessment of food additives. Risk Analysis, 36(1), $130-144$.

BElluCO, S., LOSASSO, C., MAGGiOletTI, M., AlONZI, C. C., PAOLETTI, M. G. \& RICCI, A. 2013. Edible Insects in a food safety and nutritional perspective: a critical review. Comprehensive Reviews in Food Science and Food Safety, 12, $296-313$.

CASTRO, M. \& CHAMBERS, E. 2019. Willingness to eat an insect-based product and impact on brand equity: A global perspective. Journal of sensory studies, 34(2), e12486.

CICATIELLO, C., ROSA, B. \& LACETERA, N. 2016. Consumer approach to insects as food: barriers and potential for consumption in Italy. British Food Journal, 118, $2271-2286$.

COOK, A. J., KERR, G. N. \& MOORE, K. 2002. Attitudes and intentions towards purchasing GM food. Journal of Economic Psychology, 23, 557 - 572.

COOKE, R. \& FRENCH, D. P. 2011. The role of context and timeframe in moderating relationships within the theory of planned behaviour. Psychology and Health, 26(9), $1225-1240$.

COSTA-NETO, E. M. 2013. Insects as human food: an overview. Amazônica - Revista de Antropologia, 5(3), 562 - 582. Cronbach, L. J. (1951). Coefficient Alpha and the Internal Structure of Tests. Psychometrika, 16 (3), 297 - 334.

COSTA-NETO, E. M. 2015. Anthropo-entomophagy in Latin America: an overview of the importance of edible insects to local communities. Journal of Insects as Food and Feed: $1(1), 17-23$. 
WFPM-2020-0005.

CUNHA, L. M.; MOURA, A. P.; COSTA-LIMA, R. 2014. Consumers' associations with insects in the context of food consumption: comparisons from acceptors to disgusted." Insects to feed the world. Wageningen, Netherlands.

DE BOER, J., SCHOSLER, H. and AIKING, H. 2014. Meatless days or less but better? Exploring strategies to adapt Western meat consumption to health and sustainability challenges. Appetite. 76, 120-128.

DALMORO, M. \& VIEIRA, K. M. 2013. Dilemas na construção de escalas Tipo Likert: número de itens e a disposição influenciam nos resultados? Revista Gestão Organizacional, 6 (3), $161-174$.

FOOD AND AGRICULTURE ORGANISATION (FAO). 2011. O papel dos países emergentes no combate à fome. Retrieved from https://www.fao.org.br.

FAO. 2013. Edible insects: future prospects for food and feed security. Forestry Paper 171. Food and Agriculture Organization of the United Nations. Retrieved from http://www.fao.org/3/i3253e/i3253e.pdf.

FISCHELER, C. 1990. L'homnivore. Paris.

FORNELL, C. \& LARCKER, D. F. 1981. Evaluating structural equation models with unobservable variables and measurement error. Journal of Marketing Research,18(1), pp. 39-50.

GALEEN, C., PANTIN-SOHIER, G. \& PEYRAT-GUILLARD, D. 2018. Cognitive acceptance mechanism of discontinuous food innovations: the case of insects in France. Recherche et Applications en Marketing. September. Pp. 1-26

\section{GAZZONI, D.L. 2013. Segurança alimentar. Revista Cultivar. Retrieved from} https://www.revistacultivar.com.br.

GRACA, J., OLIVEIRA, A. \& CARDOSO, M.M. 2015. Meat, beyond the plate. Data driven hypothesis for understanding consumer willingness to adopt a more plant- 
WFPM-2020-0005.

based diet. Appetite, 90, 8—90.

HAIR, J. F., BLACK, W. C., BABIN, B. J., ANDERSON, R. E. and TATHAM, R. L. 2009. Análise multivariada de dados. Bookman.

HARTMAN, C., SHI, J., GIUSTO, A. and SIEGRIST, M. 2015. The psychology of eating insects: A cross-cultural comparison between Germany and China. Food Quality and Preference, 44, 148 - 156.

INSTITUTO BRASILEIRO DE GEOGRAFIA E ESTATISTICA (IBGE). 2018. Populaçao do Brasil. Available from: https://www.ibge.gov.br/en/statistics/social/population.html

KHAN, R.S., KIAT, S.L. \& GRIGOR, J.M. 2017 Characterization of food product innovation practices with reference to functional food product development in Singapore. Asian Journal of Agriculture and Food Sciences, 5(2), 30-39.

LA BARBERA, F., VERNAU, F. AMATO, M. \& GRUNERT, K. 2018. Understanding westerner's disgust for the eating of insects: the role of food neophobia and implicit associations. Food Quality and Preference. 64, 120-125.

LENSVELT, E. J. S. \& STEENBEKKERS, L. P. A. 2014. Exploring consumer acceptance of Entomophagy: a survey and experiment in Australia and the Netherlands. Ecology of Food and Nutrition, 53 (5), 543-561. Taylor and Francis.

LOBB, A. E., MAZZOCCHI, M. \& TRAIL, W. B. 2007. Modelling risk perception and trust in food safety information within the theory of planned behaviour. Food Quality and Preference, 18, $384-395$.

MACEDO, I. M. E., VELOSO, R., MEDEIROS, H. A. F., PADILHA, M. R. F., FERREIRA, G. S. \& SHINOHARA, N. K. S. 2017. Entomophagy in different food cultures. Revista Geama, 9 (1), 22 - 26.

MALHOTRA, N. 2011. Pesquisa de marketing: Foco na Decisão (3rd ed.). Pearson 
WFPM-2020-0005.

Prentice Hall.

MANCINI, S., MORUZZO, R., RICCIOLI, F. and PACI, G. 2019. European consumers' readiness to adopt insects as food: a review. Food Research international. 122, 661-678.

MAZZOCCHI, M., LOBB, A. and TRAIL, W.B. 200.) The SPARTA model: an econometric analysis of consumers behaviour under risk. In proceedings of the 99 $9^{\text {th }}$ EAAE Seminar, Bonn, February.

MENOZZI, D., SOGARI, G., VENEZIANI, M., SIMONI, E. \& MORA, C. 2017. Eating novel foods: An application of the Theory of Planned Behaviour to predict the consumption of an insect-based product. Food Quality and Preference, 59, $27-34$.

MIGNON, J. 2002. L'entomophagies: une question de culture? Tropicultura, 20 (3), 151-155.

DO NASCIMENTO, J. C. H. B. \& MACEDO, M. A. 2016. Modelagem de equações estruturais com mínimos quadrados parciais: um exemplo da aplicação do SmartPLS R em pesquisas em contabilidade. Revista de Educação e Pesquisa em Contabilidade, v. 10, n. 3, p. 289 - 313.

PAS, L. V. D. 2017. Dutch consumers' willingness to try insects: the influence of food choice motives on intentions (MSc Applied Communication Science). Wageningen - university \& research.

PAUPERIO, A., SEVERO, M., LOPES, C., MOREIRA, P., COOKE, L. \& OLIVEIRA, A. 2014. Could the food neophobia scale be adapted to pregnant women? A confirmatory factor analysis in a Portuguese sample. Appetite, 75, 110 $-116$.

PLINER, P. and HOBDEN, K. 1992. Development of a scale to measure the trait of 
WFPM-2020-0005.

food neophobia in humans. Appetite, 19 (2), $105-120$.

RINGLE, C. M., DA SILVA, D. \& BIDO, D. D. S. 2014. Modelagem de equações estruturais com utilização do SmartPLS. Revista Brasileira de Marketing, 13(2), pp. 56-73.

RITCHEY, P. N., FRANK, R. A., HURSTI, U. \& TUORILA, H. 2003. Validation and cross-national comparison of the food neophobia scale (FNS) using confirmatory factor analysis. Appetite, 40, 163 - 173.

ROZN, P. \& FALLON, A.E. 1987. A perspective on disgust. Psychological Review, 94(1), 23-41.

SABATE, J. \& SORET, S. 2014. Sustainability of plant-based diets: back to the future. The American Journal of Clinical Nutrition, 100, 476S- 482S.

SCHUMACKER, R. E. \& LOMAX, R. G. 2010. A Beginner's guide to structural equation modeling (3rd ed.). Springer.

SCHOSLER, H., DE BOER, J. \& BOERSEMA, J.J. (2012). Can we cut out the meat of the dish? Constructing consumer-oriented pathways towards meat substitution. Appetite, 58, 39-47.

SCHARDONG, I. S., FREIBERG, J. A., SANTANA, N. A. \& RICHARD, N. S. P. R. 2019. Brazilian consumers' perception of edible insects. Ciência Rural. 49:10.

SILVA, S. D. \& COSTA, F. J. 2014. Mensuração e escalas de verificação: uma análise comparativa das escalas de Likert e Phrase Completion. PMKT - Revista Brasileira de Pesquisas de Marketing, Opinião e Mídia, 15, 1 - 16.

SOGARI, G., MENOZI, D. \& MORA, C. 2018. The food neophobia scale and young adults' intention to eat insect products. International Journal of Consumer Studies, 43 , pp. $68-76$. 
WFPM-2020-0005.

1 STEPTOE, A., POLLARD, T. M. \& WARDLE, J. 1995. Development of a measure of the motives underlying the selection of food: the food choice questionnaire. Appetite, 25, $267-284$.

TAN, H. S. G., FISCHER, A. R., TINCHAN, P., STIEGER, M., STEENBEKKERS, L. \& TRIJP, H. V. 2015. Insects as food: exploring cultural exposure and individual experience as determinants of acceptance. Food Quality and Preference, $42,78-89$.

TAO, J. \& LI, Y.O. 2018. Edible insects as a means to address global malnutrition and food insecurity issues. Food Quality and Safety. 2(1), 17-26.

TILMAN, D. and CLARK, M. 2014. Global diets link environmental sustainability and human health. Nature, 515, 518-522.

TUORILA, H., LAHTEENMAKI, L. P., POHJALAINEN, L.\& L. 2001. Food neophobia among the Finns and related responses to familiar and unfamiliar foods. Food Quality and Preference. 12. Pp. 29-37.

United Nations (UN). 2015. Insects as livestock. Available from:

https://sustainabledevelopment.un.org/content/documents/12867Policybrief_Insects.pd $\underline{\mathrm{f}}$

United States Department of Agriculture (USDA). 2020. Livestock and poultry: world markets and trade. January. Available from: https://apps.fas.usda.gov/psdonline/circulars/livestock_poultry.pdf

VAN HUIS, A., ITTERBEECK, J.V., KLUNDER, H., MERTENS, E., HALLORAN, A., MUIR, G. \& VANTOMME, P. 2013. Edible insects: future prospects for food and feed security. Forestry Paper. FAO. 171

VEECK, A. 2010. Encounters with extreme foods: neophilic/neophobic tendencies and novel foods. Journal of Food Products Marketing, 16(2), pp. 246-260. 
WFPM-2020-0005.

1 VERBEKE, W. 2015. Profiling consumers who are ready to adopt insects as a meat 2 substitute in a Western society. Food Quality and Preference,1(39), 147 - 155.

3 VERnAU, F., BARBERA, F. L., KOLLE, S., AMATO, M., GIUDICE, T. \& GRUNERT, K. 2016. The effect of communication and implicit associations on consuming insects: An experiment in Denmark and Italy. Appetite, 106, 30 - 36.

6 VIGITEL. 2015. Vigitel Brasil 2015 - Saúde Suplementar. [on-line] Available from:www.ans.gov.br

WOOLF, E., ZHUA, Y., EMORY, K., ZHAO, J. \& LIU, C. 2019. Willingness to consume insect-containing foods: A survey in the United States. LWT Food Science and Technology. 102, pp. 100-105. 